\title{
The Treatment of Distal Biceps Ruptures: An Overview
}

\author{
Simone Cerciello ${ }^{1,2}$ Enrico Visonà ${ }^{3}$ Katia Corona ${ }^{4}$ Paulo Roberto Ribeiro Filho ${ }^{5}$ Stefano Carbone ${ }^{6}$ \\ 1 Ortopedia, Casa di Cura Villa Betania, Rome, Italy \\ ${ }^{2}$ Ortopedia, Marrelli Hospital, Crotone, Italy \\ 3 Ortopedia 1-Istituto Clinico Città di Brescia, Brescia, Italy \\ ${ }^{4}$ Dipartimento di Statistica, Università degli Studi del Molise, \\ Campobasso, Italy \\ 5 Orthopedic Department, Hospital Nossa Senhora dos Prazeres, \\ Santa Catarina, Brazil \\ 6 Ortopedia, Ospedale san Camillo de Lellis, Rieti, Italy \\ Address for correspondence Enrico Visonà, MD, Ortopedia 1-Istituto \\ Clinico Città di Brescia, via B. Gualla 15, Brescia, Italy \\ (e-mail: enricovisona@icloud.com).
}

Joints 2018;6:228-231.

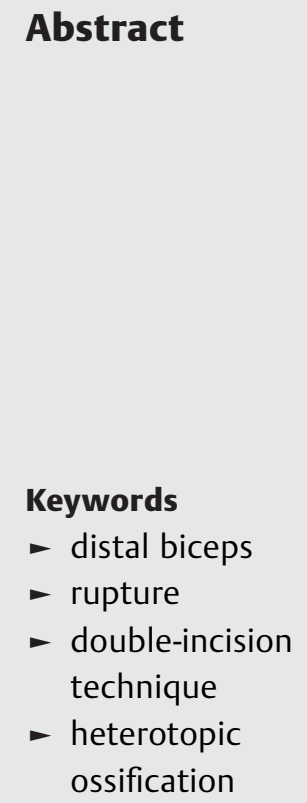

Traumatic lesions of the distal biceps brachii are uncommon. They often result from rapid elbow flexion against resistance. Conservative treatment is only indicated in lowdemanding patient and in those who have severe comorbidities. Regarding the surgical approach, two options are available: the single- and the double-incision techniques. The former has been the first to be described and was associated with significant rate of neurologic complications. The second showed less frequent neurologic lesions, but considerable rate of heterotopic ossifications with reduced forearm movement. The choice of fixation device is another important issue. Cortical buttons, transosseous repair, suture anchors, and interference screws have shown satisfactory outcomes. However, cortical buttons have the best mechanical properties. Although a lack of high methodological quality studies emerges in the available literature, three recent systematic reviews and meta-analysis show interesting findings. Surgical reinsertion of the distal biceps brachii yields satisfactory clinical outcomes both with the singleand double-incision techniques. Higher prevalence of nerve injuries is associated with the single-incision techniques, whereas higher prevalence of heterotopic ossification is reported with double-incision techniques. Thus far, there is no sufficient evidence to support one option and the choice is mainly based on surgeon's experience.

\section{Introduction}

Distal biceps brachii tendon ruptures are relatively rare with a reported incidence of 1.2 per 100,000 inhabitants per year. ${ }^{1}$ They generally affect males between the fourth and sixth decades often practicing strenuous sports such as heavyweight lifting. ${ }^{2}$ The dominant extremity is usually affected in more than $80 \%$ of cases and smokers have a 7.5 times greater risk of injury compared with nonsmokers. ${ }^{3}$ Patients often refer to a history of rapid elbow flexion against resistance that ends in acute pain and sudden loss of strength. ${ }^{4}$ Although several pathogenic theories have been proposed, the hypovascular zone hypothesis seemed to be the most valid. Seiler et al showed a consistent hypovascular zone of $2.14 \mathrm{~cm}$ in diameter corresponding to the areas of focal degeneration seen on light microscopy of ruptured tendons. ${ }^{5}$ The same authors demonstrated that the distance between the lateral border of the ulna and the radial tuberosity, which is the space occupied by the tendon, was reduced by $48 \%$ when the forearm was held in full supination. Therefore, a mechanical impingement in forced supination may play an additional role. ${ }^{5}$ Other reported factors include use of anabolic steroids ${ }^{6}$ and the presence of bone spicules or a peculiar shape of the radial received

September 11, 2017

accepted after revision

August 7, 2019

published online

October 11, 2019
DOI https://doi.org/

10.1055/s-0039-1697615. ISSN 2282-4324.
Copyright @ 2018 Georg Thieme Verlag

KG Stuttgart · New York
License terms

(®) $\Theta \circledast$ 
tuberosity with an acute edge. ${ }^{7,8}$ However, there is often a combination of local anatomical factors and intrinsic tendon degeneration, contributing to the failure of the distal biceps tendon. ${ }^{5}$ Patients usually report acute pain in the cubital fossa during an eccentric exercise, sometimes associated with an audible pop, edema, and superficial ecchymosis and a palpable defect in the distal aspect of the tendon. ${ }^{8}$ In the subacute setting, reduced strength in forearm supination and elbow flexion is common.

\section{Treatment Options}

Both conservative and surgical approaches have been proposed. First reports highlighted the advantages of conservative treatment since it was easier, safer, quicker, and satisfying in terms of outcomes when compared with surgery. ${ }^{9}$ However, biomechanical studies demonstrated loss from 21 to $55 \%$ in supination strength, $86 \%$ in supination resistance, loss from 8 to $36 \%$ in flexion strength, and $62 \%$ in flexion resistance after nonsurgical approach. ${ }^{10}$ Freeman et al reported the outcomes of a comparative study. In the conservative group, mean supination and flexion strengths were 74 and $88 \%$ of the contralateral arm. Worse results were observed when the dominant arm was affected. Patients with unrepaired rupture had a significant difference in supination strength (74\% compared with $101 \%$ ) but not in flexion strength $(88 \%$ compared with $97 \%) .{ }^{11}$ In addition, the attempt to adapt to the new situation generally results in an increased use of the shoulder muscles, with abduction of the shoulder and the arm while externally rotating the forearm to increase supination power. ${ }^{12}$ Therefore, nonoperative treatment is generally proposed to sedentary and low-demanding patients and to those who are not medically fit for operative treatment. ${ }^{3}$

Surgical reinsertion to the radial tuberosity may be achieved through one or two incisions and with different devices. Timing must be carefully considered, since in case of delayed surgery, the tendon is generally retracted proximally and sometimes it is impossible to bring it back to the radius. ${ }^{13}$ Moreover, healing process starts early after injury, and scar tissue may obliterate the original location of the tendon making surgery challenging. The first attempt to suture the distal biceps tendon to the radial tuberosity was reported in 1898 , while the first reinsertion with a device (a nail) was reported in $1928 .^{9}$

Surgical repair was initially performed with a direct anterior approach ( - Fig. 1) between the brachioradialis and pronator teres. A single $4-\mathrm{cm}$ transverse incision or a " $\mathrm{S}$ "-

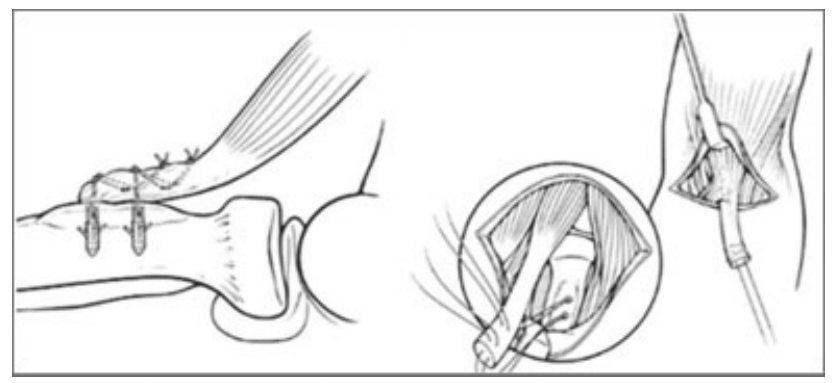

Fig. 1 The single-incision approach. shaped incision can be used. The lateral antebrachial cutaneous nerve and cephalic vein are often encountered and must be preserved. Once the biceps stump is located in the proximal part, it should be mobilized and freed from surrounding scar tissue or adhesions. The radial tuberosity is usually exposed by dissecting a plane with finger or other blunt instrument. Using Hohmann retractors as needed, with the arm maximally supinated, the footprint of the biceps tendon on the radial tuberosity should be visualized. Although this option provided good tendon and radial tuberosity exposure, it was associated with high rate of radial nerve palsies $(4.4 \%){ }^{9}$

A double-incision approach (-Fig. 2) was described in 1961 in the attempt to provide wide area of reinsertion and reduced rates of radial nerve complications. ${ }^{14}$ The anterior approach was intended for retracted biceps harvesting; the tendon was then passed from front to back between the pronator teres and brachioradialis. With the arm in maximal pronation to protect the posterior interosseous nerve, a curved clamp should be passed medially to the radial tuberosity between the radius and ulna and directed posteriorly. It is important to avoid damaging the periosteum on the ulna. The clamp is passed through the common extensor muscles and is palpated subcutaneously. A posterior approach is then made, splitting the fibers of the common extensor origin. The tendon was retrieved between the ulna and anconeus and then sutured to bone.

The major drawback of this combined approach was the occurrence of heterotopic ossifications (HOs) between the proximal radius and ulna, which resulted in a reduced range of movement (ROM). This was thought to be caused by detachment of the anconeus off the ulna thus damaging its periosteum and the interosseous membrane. ${ }^{15}$ This anatomic damage was then responsible for HO formation. ${ }^{16,17}$ To prevent this complication, Morrey et al recommended to split the

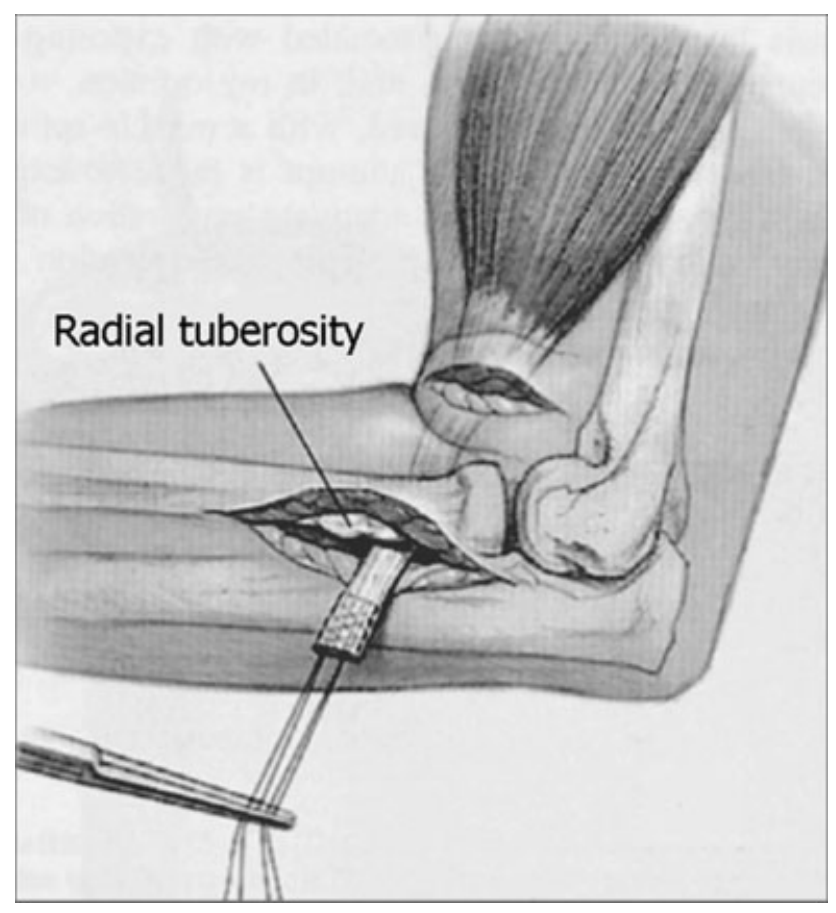

Fig. 2 The double-incision approach. 
extensor carpi ulnaris or the extensor digitorum communis instead of detaching the anconeus and to carefully remove bone debris. ${ }^{7}$ With these tips, which have been described as the modified double-incision technique, the authors did not observe anymore ROM-limiting HO. ${ }^{18}$

\section{Double-Incision Techniques}

The outcomes of double-incision techniques are generally satisfactory; however, the fixation device may influence results. The ultimate goal is the strongest fixation to allow early movement thus preventing stiffness and HO. Mechanical strength studies have demonstrated that cortical buttons have the best mechanical properties compared with transosseous repair, suture anchors, or interference screws. ${ }^{19,20}$ Single-suture anchors have lower strength than transosseous repairs, ${ }^{21}$ while double-suture anchors have higher strength than transosseous repairs. ${ }^{22}$ Finally interference screws yield constructs that are closest to the ultimate tensile load and stiffness of intact tendon. ${ }^{23}$ However, the analysis of the literature is quite confusing both regarding the outcomes and complication rates since most of data refer to case series studies with low methodological power.

In a systematic review of 2008, the outcomes and complications of both single- $(n=165)$ and double-incision $(n=142)$ techniques were reported. ${ }^{24}$ The satisfactory outcomes in the single-incision group were 135 (94\%), whereas the unsatisfactory outcomes were 8 (6\%). In the double-incision group, corresponding values were 60 (69\%) and 27 (31\%). There was a significantly higher number of unsatisfactory results in the double-incision group $(p<0.01)$, with loss of forearm rotation (11 elbows, $12 \%$ ) and/or loss of rotational strength (18 elbows, $19 \%$ ) being the most common reasons for these results. However, no difference in the overall incidence of complications between single-incision approaches (18\%) and double-incision approaches (16\%) was reported.

A more recent systematic review of 22 studies $^{25}$ evaluated the complication rates of single- $(n=327)$ and double-incision ( $n=171$ ) techniques. The total number of patients was 494 (498 elbows), with 327 in the single-incision group and 171 in the double-incision group. The overall complication rate was $24.5 \%$ ( 122 of 498 elbows). It was $23.9 \%$ ( 78 of 327 ) for singleincision technique and $25.7 \%$ (44 of 171) for double-incision technique ( $p=0.32$ ). The complication rate was $26.4 \%$ (75 of
284) for suture anchors, $20.4 \%$ (34 of 167) for bone tunnels, $44.8 \%$ ( 13 of 29 ) for intraosseous screws, and $0 \%$ ( 0 of 18 ) for cortical button fixation. The complication rate for use of bone tunnels was significantly lower than that for intraosseous screws $(p<0.01)$. Similarly, the cortical button method proved superior to intraosseous screws $(p=0.01)$. The most common complication was lateral antebrachial cutaneous nerve neurapraxia (9.6\% across all studies, $11.6 \%$ for single incision, and $5.8 \%$ for double incisions).

A recent meta-analysis compared the complication rates and specific complications of the single-incision techniques and the double-incision techniques. ${ }^{26}$ The overall complication rate in the double-incision group $(n=498)$ was $20.9 \%$. The rate was lower when compared with those of the single-incision group $(n=785)$, which was $28.3 \%$. Similarly to what has been previously reported, HO was the most common complication in the double-incision group with a reported rate of $7.2 \%$ (36/498). Neurapraxia was reported in $2.2 \%(11 / 498)$ of cases. Re-rupture and or failure of the reinsertion devices occurred in $0.6 \%$ (3/498) of cases; all three cases were transosseous reinsertions. Additional complications included superficial wound infection (5/498), nerve paresthesia (2/498), nerve dysesthesia (3/498), anterior interosseous nerve palsy (1/498), ulnar nerve palsy (1/ 498), and other complications ranging from sterile stitch abscesses to lateral antebrachial cutaneous nerve neuritis (30/498). The authors concluded that there is consistently inferior rate $(p=0.003)$ of complication in case of doubleincision techniques compared with single-incision ones.

In recent study, ${ }^{27}$ the complications of 784 distal biceps repair were analyzed. The treatment was performed through a single-incision technique in 639 cases, whereas the rest was treated by means of a double-incision technique. The double-incision technique showed a higher rate of posterior interosseous nerve palsy ( $3.4 \mathrm{vs} .0 .8 \%, p=0.010$ ), heterotopic bone formation ( $7.6 \mathrm{vs.} 2.7 \%, p=0.004)$, and reoperation rate ( 8.3 vs. $2.3 \%, p=0.001$ ), whereas the single-incision technique showed a higher rate of lateral antebrachial cutaneous nerve palsy ( 24.4 vs. $4.1 \%, p=0.001$ ).

According to these data (see - Table $\mathbf{1}$ ), the choice between single- and double-incision techniques is still guided by the surgeon's comfort and training. Outcomes are comparable between the two cohorts. Intraoperative complications are more frequent after single-incision techniques as a

Table 1 Number of patients, outcomes, and complications of single-incision and double-incision technique in the literature

\begin{tabular}{|l|l|l|l|l|l|l|l|}
\hline & & $\begin{array}{l}\text { No. of } \\
\text { patients }\end{array}$ & $\begin{array}{l}\text { Satisfactory } \\
\text { outcomes }\end{array}$ & $\begin{array}{l}\text { Unsatisfactory } \\
\text { outcomes }\end{array}$ & $\begin{array}{l}\text { No. of } \\
\text { complications }\end{array}$ & $\begin{array}{l}\text { Nerve } \\
\text { palsy }\end{array}$ & $\begin{array}{l}\text { Heterotopic } \\
\text { ossifications and } \\
\text { loss of ROM }\end{array}$ \\
\hline Chavan et al $2008^{24}$ & Single-incision & 165 & $135(94 \%)$ & $8(6 \%)$ & $29(18 \%)$ & $20(10 \%)$ & $8(5 \%)$ \\
\hline Watson et al $2014^{25}$ & Single-incision & 327 & na & na & $78(23.9 \%)$ & $11.6 \%$ & $10(3.1 \%)$ \\
\hline Amin et al $2016^{26}$ & Single-incision & 785 & na & na & $222(28.2 \%)$ & $77(9.8 \%)$ & $25(3.2 \%)$ \\
\hline Chavan et al $2008^{24}$ & Double-incision & 142 & $60(69 \%)$ & $27(31 \%)$ & $23(16 \%)$ & $10(7 \%)$ & $21(15 \%)$ \\
\hline Watson et al $2014^{25}$ & Double-incision & 171 & na & na & $44(25.7 \%)$ & $5.8 \%$ & $21(7 \%)$ \\
\hline Amin et al $2016^{26}$ & Double-incision & 498 & na & na & $104(20.4 \%)$ & $11(2.2 \%)$ & $36(7.2 \%)$ \\
\hline
\end{tabular}

Abbreviations: na, not available; ROM, range of motion. 
consequence of nerve injuries. HOs are responsible for the majority of unsatisfactory results in the double-incision group. Similarly there is no definitive evidence to support one method of fixation over another. However, laboratory studies have demonstrated biomechanically stronger fixation with cortical buttons or hybrid methods involving cortical buttons and an interference screw. This has no clinical relevance, since no difference has been demonstrated in terms of re-rupture rates or implant failures but stronger fixation devices may allow a more aggressive rehabilitation protocols.

\section{Conclusion}

Surgical reinsertion of the distal biceps brachii is a successful procedure with satisfactory clinical outcomes and acceptable complication rate. Thus far, there is no clear evidence to support the choice between single- and double-incision techniques and between different fixation methods. Higher rates of nerve injuries should be expected with the singleincision techniques, whereas higher prevalence of HOs is reported with double-incision techniques. In addition, biomechanical studies have shown the superiority of cortical buttons over others methods. However, it does not reflect on better functional outcomes or reduced re-rupture rates. Therefore, there is no sufficient evidence to support one of these options and the choice of which approach to use is mainly based on surgeon's experience.

\section{Conflict of Interest}

None declared.

\section{References}

1 Safran MR, Graham SM. Distal biceps tendon ruptures: incidence, demographics, and the effect of smoking. Clin Orthop Relat Res 2002;(404):275-283

2 D'Alessandro DF, Shields CL Jr, Tibone JE, Chandler RW. Repair of distal biceps tendon ruptures in athletes. Am J Sports Med 1993; 21(01):114-119

3 Miyamoto RG, Elser F, Millett PJ. Distal biceps tendon injuries. J Bone Joint Surg Am 2010;92(11):2128-2138

4 Leighton MM, Bush-Joseph CA, Bach BR Jr. Distal biceps brachii repair. Results in dominant and nondominant extremities. Clin Orthop Relat Res 1995;(317):114-121

5 Seiler JG III, Parker LM, Chamberland PD, Sherbourne GM, Carpenter WA. The distal biceps tendon. Two potential mechanisms involved in its rupture: arterial supply and mechanical impingement. J Shoulder Elbow Surg 1995;4(03):149-156

6 Visuri T, Lindholm H. Bilateral distal biceps tendon avulsions with use of anabolic steroids. Med Sci Sports Exerc 1994;26(08): 941-944

7 Morrey BF, Askew LJ, An KN, Dobyns JH. Rupture of the distal tendon of the biceps brachii. A biomechanical study. J Bone Joint Surg Am 1985;67(03):418-421

8 Baker BE, Bierwagen D. Rupture of the distal tendon of the biceps brachii. Operative versus non-operative treatment. JBone Joint Surg Am 1985;67(03):414-417
9 Dobbie RP. Avulsion of the lower biceps brachii tendon: analysis of fifty-one previously unreported cases. Am J Surg 1941; 51:662-683

10 Freeman CR, McCormick KR, Mahoney D, Baratz M, Lubahn JD. Nonoperative treatment of distal biceps tendon ruptures compared with a historical control group. J Bone Joint Surg Am 2009; 91(10):2329-2334

11 El-Hawary R, Macdermid JC, Faber KJ, Patterson SD, King GJ. Distal biceps tendon repair: comparison of surgical techniques. JHand Surg Am 2003;28(03):496-502

12 Meherin JM, Kilgore ES. The treatment of ruptures of the distal biceps brachii tendon. Am J Surg 1960;99:636-640

13 Boyd HB, Anderson LD. A method for reinsertion of the distal biceps brachii tendon. J Bone Joint Surg 1961;43:1041-1043

14 Failla JM, Amadio PC, Morrey BF, Beckenbaugh RD. Proximal radioulnar synostosis after repair of distal biceps brachii rupture by the two-incision technique. Report of four cases. Clin Orthop Relat Res 1990;(253):133-136

15 Karunakar MA, Cha P, Stern PJ. Distal biceps ruptures. A followup of Boyd and Anderson repair. Clin Orthop Relat Res 1999;(363):100-107

16 Davison BL, Engber WD, Tigert LJ. Long term evaluation of repaired distal biceps brachii tendon ruptures. Clin Orthop Relat Res 1996;(333):186-191

17 Morrey BF. Tendon injuries about the elbow. In: Morrey BF, Sanchez-Sotelo J, eds. The Elbow and Its Disorders. Philadelphia: WB Saunders; 1993:492-504

18 Kelly EW, Morrey BF, O'Driscoll SW. Complications of repair of the distal biceps tendon with the modified two-incision technique. J Bone Joint Surg Am 2000;82(11):1575-1581

19 Sethi P, Obopilwe E, Rincon L, Miller S, Mazzocca A. Biomechanical evaluation of distal biceps reconstruction with cortical button and interference screw fixation. JShoulder Elbow Surg 2010;19 (01):53-57

20 Siebenlist S, Buchholz A, Zapf J, et al. Double intramedullary cortical button versus suture anchors for distal biceps tendon repair: a biomechanical comparison. Knee Surg Sports Traumatol Arthrosc 2015;23(03):926-933

21 Pereira DS, Kvitne RS, Liang M, Giacobetti FB, Ebramzadeh E. Surgical repair of distal biceps tendon ruptures: a biomechanical comparison of two techniques. Am J Sports Med 2002;30(03): 432-436

22 Lemos SE, Ebramzedeh E, Kvitne RS. A new technique: in vitro suture anchor fixation has superior yield strength to bone tunnel fixation for distal biceps tendon repair. Am J Sports Med 2004;32 (02):406-410

23 Idler CS, Montgomery WH III, Lindsey DP, Badua PA, Wynne GF, Yerby SA. Distal biceps tendon repair: a biomechanical comparison of intact tendon and 2 repair techniques. Am J Sports Med 2006;34(06):968-974

24 Chavan PR, Duquin TR, Bisson LJ. Repair of the ruptured distal biceps tendon: a systematic review. Am J Sports Med 2008;36 (08):1618-1624

25 Watson JN, Moretti VM, Schwindel L, Hutchinson MR. Repair techniques for acute distal biceps tendon ruptures: a systematic review. J Bone Joint Surg Am 2014;96(24):2086-2090

26 Amin NH, Volpi A, Lynch TS, et al. Complications of distal biceps tendon repair: a meta-analysis of single-incision versus doubleincision surgical technique. Orthop J Sports Med 2016;4(10): 2325967116668137

27 Dunphy TR, Hudson J, Batech M, Acevedo DC, Mirzayan R. Surgical treatment of distal biceps tendon ruptures: an analysis of complications in 784 surgical repairs. Am J Sports Med 2017;45(13): 3020-3029 